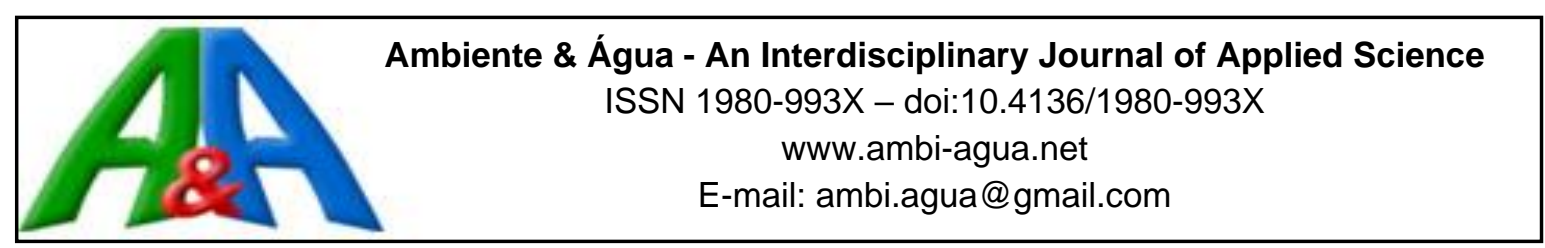

\title{
Roteiro para avaliação da qualidade da água de uma bacia hidrográfica por alunos do ensino fundamental
}

\author{
doi:10.4136/ambi-agua.1893
}

Received: 12 Jun. 2016; Accepted: 11 Sep. 2016

\author{
Cheila Flávia de Praga Baião ${ }^{*}$; Getulio Teixeira Batista ${ }^{1}$ \\ ${ }^{1}$ Universidade de Taubaté (UNITAU), Taubaté, SP, Brasil \\ Programa de Pós-Graduação em Ciências Ambientais \\ *Autor correspondente: e-mail: cheilabaiao77@gmail.com, \\ gtbatista@gmail.com
}

\section{RESUMO}

Neste trabalho foi desenvolvido um roteiro de atividades de análise físico-químicomicrobiológica da água de uma bacia hidrográfica para aplicação por alunos do $6^{\circ}$ e $7^{\circ}$ anos do Ensino Fundamental e avaliado o resultado do aprendizado dos alunos para o entendimento do grau de preservação da bacia estudada. Os procedimentos metodológicos envolveram: trabalho de campo com os alunos, orientação sobre os elementos presentes na água, análise físicoquímica, comparações com os padrões estabelecidos na Resolução CONAMA N 357, análise microbiológica e discussão dos resultados. Os resultados apontaram presença de amônia e fosfato fora dos padrões legais, assim como a presença de coliformes termotolerante. Dos 60 alunos envolvidos, $70 \%$ concluíram a atividade proposta, de forma adequada, associando os resultados encontrados à presença de esgoto e lixo. Um questionário pós-atividade apontou que os alunos passaram a reconhecer os elementos físico-químico-microbiológicos presentes no rio, assim como intervenções humanas que podem causar prejuízos à qualidade da água. O roteiro proposto mostrou-se adequado pois os alunos construíram conceitos, desenvolveram procedimentos experimentais e levantaram hipóteses pertinentes a cerca dos problemas ambientais.

Palavras-chave: análise físico-química-microbiológica, educação ambiental, roteiro de atividades.

\section{Script for analysis of water quality of a watershed for use by elementary school students}

\begin{abstract}
In this work we developed a script for the physico-chemical and microbiological analysis of water from a watershed to be used by students of the $6^{\text {th }}$ and $7^{\text {th }}$ grades of elementary school and evaluated the results of the students in learning to understand the degree of preservation of the study area. The methodological procedures involved field work with students, guidance in understanding the elements present in the water, physical and chemical analysis, comparisons with standards set by CONAMA Resolution No. 357, microbiological analysis and discussion of results. The results showed the presence of ammonia and phosphate exceeding legal standards and the presence of fecal coliforms. Of the 60 students involved, $70 \%$ completed the proposed activity in an appropriate manner and associated the results with the occurrence of
\end{abstract}


sewage and garbage. A post-activity questionnaire showed that students became able to recognize the physico-chemical and microbiological elements present in the river, as well as human interventions that can damage water quality. The proposed script was adequate for the students to build concepts and to develop experimental procedures and relevant hypotheses about environmental problems.

Keywords: activities script, environmental education, physico-chemical-microbiological analysis.

\section{INTRODUÇÃO}

A Bacia Hidrográfica é uma unidade natural que possibilita uma visão integrada de diversos processos ambientais e que envolve interações antrópicas, econômicas e sociais com os processos biogeofísicos (Lucatto e Talamoni, 2007). E, portanto, é definida pela Política Nacional de Recursos Hídricos como unidade territorial de gerenciamento das águas (Brasil, 1997). Entretanto, a garantia de sustentabilidade dessa gestão está atrelada à disponibilidade de informações para a sociedade, ao controle de impactos sobre os sistemas hídricos e a tomada de decisão voltada para a comunidade, respeitando os limites impostos pela aptidão natural das bacias hidrográficas (Porto e Porto, 2008).

A avaliação da qualidade da água é realizada pela CETESB desde 1975, com o cálculo do IQA (Índice de Qualidade das Águas) por bacia contribuindo para o gerenciamento ambiental das 22 Unidades de Gerenciamento dos Recursos Hídricos do Estado de São Paulo (CETESB, 2008).

O IQA avalia a qualidade da água por meio dos seguintes parâmetros: Oxigênio dissolvido, Coliformes termotolerante, potencial hidrogeniônico $(\mathrm{pH})$, demanda bioquímica de oxigênio (DBO), temperatura da água, nitrogênio total, fósforo total, turbidez e resíduo total. A ocorrência desses elementos fora dos padrões estabelecidos pela legislação pode indicar a presença de agentes poluidores, como lançamentos de esgotos ou resíduos industriais (Parron et al., 2011).

O estudo da bacia por meio da análise dos parâmetros de qualidade da água pode ser utilizado em programas ambientais de instituições de ensino, pois além de contemplar tópicos de conteúdos desenvolvidos nas escolas, colabora para o desenvolvimento de uma consciência crítica, participativa e responsável sobre a preservação da água (Belo e Paranhos, 2011). Também pode contribuir para um processo em que são trabalhados compromissos e conhecimentos capazes de levar o indivíduo a repensar sua relação com o meio (Schiel et al., 2002), e, na maioria promove a co-responsabilização para o desenvolvimento sustentável (Jacobi, 2003). Constituindo o que se define por Educação Ambiental, cujos processos levam o indivíduo e a coletividade a construirem valores sociais, conhecimentos, habilidades, atitudes e competências voltadas para a conservação do meio ambiente (Brasil, 1999).

Este trabalho quando realizado em bacias urbanas, pode aumentar a percepção dos alunos, permitindo que visualizem a legitimidade e a utilidade dos aspectos ecológicos da paisagem, motivando-os para o envolvimento na preservação ambiental das cidades (Kudryavtsev et al., 2012). Pode permitir também que a população tome consciência da precariedade dos serviços públicos sanitários de sua região (Curutchet et al., 2011). Conhecimentos ambientais são necessários para uma verdadeira educação da comunidade e formação de futuros gestores, o que é essencial para o desenvolvimento da gestão de recursos hídricos do século XXI (Tundisi, 2008).

No entanto, poucos trabalhos são encontrados na literatura, relatando experiências de análise de água em âmbito escolar tanto de ensino público quanto privado. Alguns exemplos são encontrados em Batista et al. (2005), Chung e Lima (2007), Zuin et al. (2009) e Belo e Paranhos (2011).

\section{IPABH}

Rev. Ambient. Água vol. 11 (suplemento) Taubaté, 2016 
Batista et al. (2005) avaliaram a água do Ribeirão das Almas, em Taubaté (SP) com alunos do Ensino Fundamental da Escola Municipal Mario Lemos de Oliveira, utilizando um kit de análise da qualidade da água, que permitia a determinação do $\mathrm{pH}$, oxigênio dissolvido, fósforo, nitrogênio, DBO, temperatura e turbidez. Ainda foram realizadas análises de Coliformes no Laboratório de Processos Biológicos Aplicados ao Meio Ambiente da Universidade de Taubaté.

Chung e Lima (2007) também utilizaram um kit de análise de água com alunos da rede municipal em Campos do Jordão (SP). Os parâmetros testados foram turbidez, temperatura, $\mathrm{pH}$ e solubilidade.

Zuin et al. (2009) desenvolveram um estudo de avaliação da qualidade das águas de uma bacia hidrográfica com alunos do Fundamental e Médio da Escola Estadual Prof. Sebastião de Oliveira Rocha, em São Carlos (SP). Os parâmetros utilizados foram temperatura, pH, oxigênio dissolvido e condutividade elétrica. Este trabalho possibilitou um intenso e efetivo envolvimento dos participantes, com reflexões sobre o contexto sociocultural, as concepções de progresso, os modelos econômicos e a atuação da sociedade.

Belo e Paranhos (2011) desenvolveram uma pesquisa em 10 escolas de Ensino Fundamental e Médio, sendo 7 públicas e 3 particulares, do Estado do Rio de Janeiro. Propuseram uma atividade com utilização de um Kit de análise de água desenvolvido pelo Laboratório de Hidrobiologia da Universidade Federal do Rio de Janeiro (UFRJ), cujos resultados são verificados por comparação colorimétrica. A água coletada para análise foi a da própria escola. Os parâmetros contemplados neste kit foram Amônia, Nitrito, Fósforo, pH e turbidez.

As atividades de análises de água com utilização de kit de análises promovem a motivação dos estudantes quanto aos conteúdos abordados (Belo e Paranhos, 2011). Elas permitem que se descubram os elementos que compõem o ambiente (Chung e Lima, 2007), e despertam nos alunos a importância dos recursos hídricos para a vida (Zuin et al., 2009).

A motivação gerada pela utilização do kit e a análise de água de corpos d'água próximos à escola vêm ao encontro do que é definido pelos Parâmetros Curriculares Nacionais do Ensino Fundamental de Ciências (Brasil, 1998a) e de Geografia (Brasil, 1998b) para os $6^{\circ}$ e $7^{\circ}$ anos, que propõem que o aspecto interativo da água com os seres vivos e as sociedades humanas, seja estudado em conjunto com o solo, clima, relevo e ocupação. E que estes estudos ocorram no entorno socioambiental (Brasil, 1998c).

Portanto, o objetivo deste trabalho foi elaborar, aplicar e avaliar um protocolo de avaliação da qualidade físico-químico-microbiológica da água com utilização de um kit educativo de reagentes de análise de água para aplicação por alunos dos $6^{\circ}$ e $7^{\circ}$ anos do Ensino Fundamental e avaliar o aprendizado dos alunos sobre a influência do entorno socioambiental na qualidade da água.

\section{MATERIAIS E MÉTODO}

A Bacia do Rio Comprido, sub-bacia do Rio Paraíba do Sul, é localizada na divisa entre os municípios de São José dos Campos e Jacareí, SP, e sofre impactos da expansão urbana, com forte degradação socioambiental (Makinodan e Costa, 2004). A bacia de estudo faz parte da Bacia do Rio Comprido, localizada entre as coordenadas W 45 $53^{\circ} 41^{\prime \prime} / \mathrm{S} 23^{\circ} 16^{\prime} 52^{\prime \prime}$ e W $45^{\circ}$ $54^{\prime} 13^{\prime \prime} / \mathrm{S} 23^{\circ} 17^{\prime \prime} 10^{\prime}$.

O estudo envolveu 60 alunos, na faixa etária entre 10 e 12 anos da Escola Estadual Lourdes Maria de Camargo, que se localiza próxima à área de estudo. Sendo 30 crianças do $6^{\circ}$ ano e 30 do $7^{\circ}$ ano do Ensino Fundamental, correspondente a uma classe de cada ano. O percentual da amostra é de $12,5 \%$ do total de alunos desse nível escolar. A pesquisa foi aprovada pelo Comitê de Ética em Pesquisa (CEP) da Universidade de Taubaté ( $\mathrm{n}^{\circ}$ do CAAE: 11407912.5.0000.5501) em 12 de abril de 2013. 
Para o desenvolvimento da atividade, foram selecionados 4 pontos de análise da bacia (Figura 1), em função da facilidade de acesso e a distância entre eles. As coordenadas

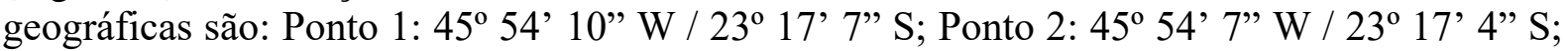

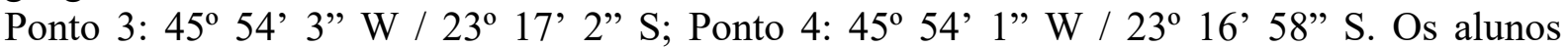
percorreram o trajeto ilustrado em amarelo na Figura 1 para reconhecimento da bacia. Nos pontos 1, 2, 3, e 4 fizeram a observação do local e coletaram a água para análise. Os $6^{\circ}$ e $7^{\circ}$ anos participaram da atividade em dias diferentes, para facilitar o trabalho em campo com um número menor de alunos.

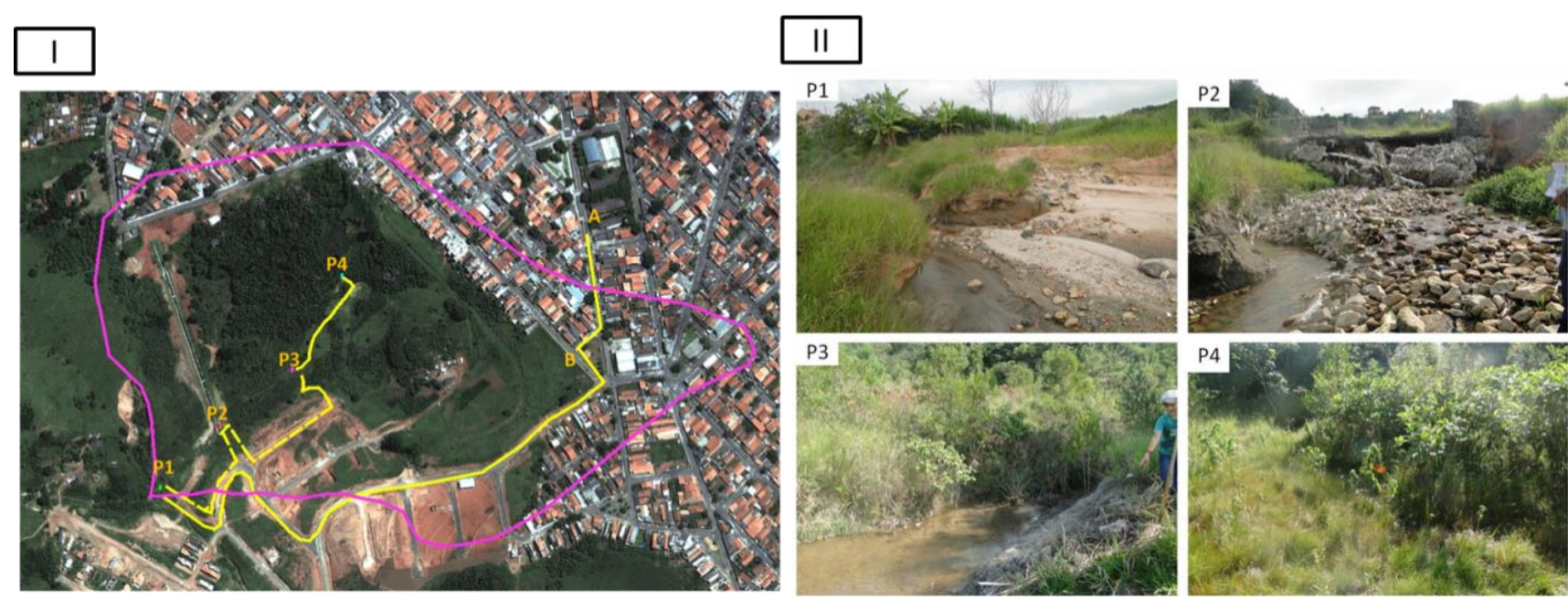

Figura 1. I - Limite da bacia de estudo em linha rosa e trajeto percorrido pelos alunos em linha amarela. II Fotografias dos pontos de análise em topossequência: Ponto 1 (P1) - exutório da bacia; Ponto 2 (P2) - escada hidráulica; Ponto 3 (P3) - balneário e Ponto 4 (P4) - nascente.

Fonte: Baião (2014).

O primeiro ponto de análise da Bacia de estudo (Figura 1, II, P1) é no exutório, caracterizado por muito acúmulo de sedimento, processos erosivos, margens cobertas por vegetação rasteira, curso d'água com fina lâmina, correnteza baixa e presença moderada de macrófitas do gênero Brachiaria. O ponto 2 (Figura 1, II, P2) é caracterizado pela presença de uma escada hidráulica para captação da água fluvial. A laje receptora apresenta desmoronamentos e muitos pedaços de concreto ficam espalhados pelo leito do rio. Nas margens são encontradas gramíneas, lixo e entulhos espalhados. O terceiro ponto (Figura 1, II, P3) apresenta arbustos característicos de vegetação pioneira, entremeados por gramíneas. A jusante, o riacho é represado e utilizado como balneário. O ponto 4 (Figura 1, II, P4) é o local mais próximo à nascente com vegetação a montante arbórea e a jusante arbustiva e herbácea em área alagada.

Todos os procedimentos metodológicos utilizados para análise da água da bacia estudada pelos alunos do Ensino Fundamental estão descritos na Figura 2.

A análise físico-química foi desenvolvida utilizando um kit educativo de análise de água da Empresa Alfakit. Este material é indicado para atividades de educação ambiental, e foi também o utilizado por Batista et al. (2005). O kit contempla reagentes para diversos parâmetros da água com fácil interpretação dos resultados, obtidos por comparação colorimétrica entre a amostra e uma tabela de cores fornecida pelo próprio kit. Os parâmetros analisados neste trabalho foram: dureza total, oxigênio dissolvido, cloretos, amônia, ferro, ortofosfato, $\mathrm{pH}$ (potencial hidrogeniônico) e turbidez. Dos parâmetros solicitados para o cálculo do IQA (Índice de qualidade da água), apenas demanda bioquímica de oxigênio (DBO) e resíduos totais não foram realizados, por demandarem mais tempo de análise. $O$ teste de dureza, não presente no IQA, foi desenvolvido, de forma que os alunos também percebessem a presença de outros

\section{IPABH}

Rev. Ambient. Água vol. 11 (suplemento) Taubaté, 2016 
elementos numa bacia. Embora o kit seja indicado para trabalhos educacionais, as análises foram desenvolvidas em conjunto professor-aluno, tomando-se os devidos cuidados de segurança.

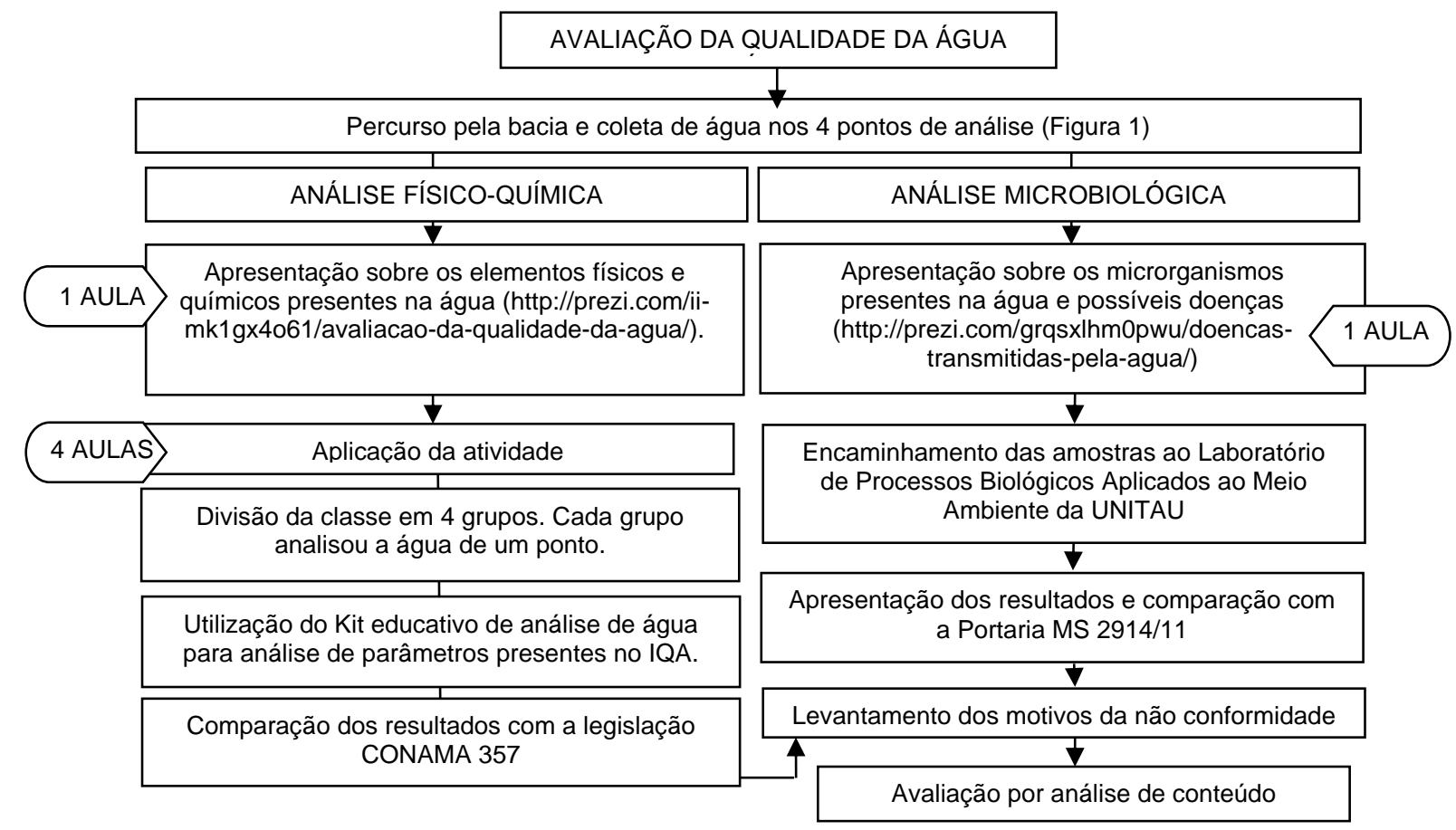

Figura 2. Fluxograma dos procedimentos utilizados para a análise físico-químicomicrobiológica da água e o número de aulas em cada etapa ( 1 aula $=50 \mathrm{~min})$.

Fonte: Baião (2014).

Os resultados da análise foram comparados aos parâmetros da Resolução CONAMA $\mathrm{n}^{\circ} 357$, a qual dispõe sobre a classificação dos corpos d'água. O trecho da bacia do Rio Paraíba do Sul estudado é enquadrado na Classe II, de acordo com a Portaria GM n ${ }^{0}$ 86/1981 do Ministério do Interior (Brasil, 1981). Corpos d'água de Classe II são águas destinadas ao abastecimento doméstico, após tratamento convencional, à irrigação de hortaliças ou plantas frutíferas e à recreação de contato primário (CONAMA, 2005).

$\mathrm{O}$ acompanhamento da sequência de atividades, bem como o registro dos resultados obtidos das análises físico-químicas realizadas pelos alunos foram feitos em uma planilha de preenchimento elaborada especificamente para este fim.

A análise microbiológica foi realizada no Laboratório de Processos Biológicos Aplicados ao Meio Ambiente da Universidade de Taubaté (UNITAU) e os resultados foram apresentados aos alunos.

Para avaliação geral do roteiro da atividade proposta, foi aplicado um questionário contendo duas perguntas discursivas sobre os elementos e interações que existem num rio e sobre o que prejudica a qualidade da água. Tanto as interpretações dos alunos sobre os resultados gerados na análise físico-química quanto as respostas do questionário pós-atividade, foram analisadas por conteúdo de acordo com Moraes (1999). As respostas do questionário pós-atividade foram agrupadas em categorias definidas após a análise, assumindo o valor 5 como frequência mínima de respostas.

\section{RESULTADOS E DISCUSSÃO}

Durante o percurso pela bacia e reconhecimento dos pontos de estudo, os alunos puderam conhecer o entorno da escola e trechos próximos de suas casas que ainda não conheciam. 
Puderam observar algumas alterações antrópicas que poderiam interferir na qualidade da água, como processos erosivos, ausência de mata ciliar, criação de animais, presença de lixo e mau cheiro. No Ponto 2, houve maior desconforto no percurso onde os alunos se depararam com o desmoronamento da laje de concreto, forte presença de lixo e um odor fétido, fazendo com que os alunos quisessem logo sair do local.

$\mathrm{O}$ embasamento teórico sobre os elementos físico-químico-microbiológicos da água foi proporcionado aos alunos por meio de apresentações em mídia disponibilizadas nos sites:

http://prezi.com/ii-mk1gx4o61/avaliacao-da-qualidade-da-agua/ e

http://prezi.com/grqsxlhm0pwu/doencas-transmitidas-pela-agua/.

Estas apresentações foram desenvolvidas especificamente para esta atividade. A dinâmica das apresentações também foi importante para despertar o interesse dos alunos sobre o tema.

Em conjunto com o professor, os alunos conseguiram realizar as análises físico-químicas e demonstraram muito interesse e entusiasmo na execução desta atividade. Com base na análise da planilha preenchida por eles (Tabela 1) é possível afirmar que 96,7\% $(n=29)$ dos alunos do $6^{\circ}$ ano e $90 \%(n=27)$ dos alunos do $7^{\circ}$ ano conseguiram comparar os resultados encontrados na análise com os parâmetros estabelecidos na Resolução CONAMA n ${ }^{\circ} 357$. Foram identificados 2 parâmetros em não conformidade com a legislação: a Amônia e o Fosfato.

Tabela 1. Análise físico-química da água em cada ponto de coleta realizada pelos alunos. Em negrito, os parâmetros em não conformidade com o estabelecido pela Resolução CONAMA no 357.

\begin{tabular}{lcccc}
\hline Parâmetros & Ponto 1 & Ponto 2 & Ponto 3 & Ponto 4 \\
\hline Temperatura da água & $19^{\circ} \mathrm{C}$ & $20^{\circ} \mathrm{C}$ & $19^{\circ} \mathrm{C}$ & $19^{\circ} \mathrm{C}$ \\
Temperatura do ar & $18,5^{\circ} \mathrm{C}$ & $18,5^{\circ} \mathrm{C}$ & $18,5^{\circ} \mathrm{C}$ & $18,5^{\circ} \mathrm{C}$ \\
Oxigênio dissolvido & $8,6 \mathrm{mg} \mathrm{L}^{-1}$ & $7,2 \mathrm{mg} \mathrm{L}^{-1}$ & $8,1 \mathrm{mg} \mathrm{L}^{-1}$ & $7,2 \mathrm{mg} \mathrm{L}^{-1}$ \\
pH & 7,0 & 8,0 & 6,5 & 7,0 \\
Amônia & $1 \mathrm{mg} \mathrm{L}^{-1}$ & $\mathbf{3 , 0 ~} \mathbf{~ m g ~ L}^{-1}$ & $1 \mathrm{mg} \mathrm{L}^{-1}$ & $2 \mathrm{mg} \mathrm{L}^{-1}$ \\
Ferro & $0,25 \mathrm{mg} \mathrm{L}^{-1}$ & $0,25 \mathrm{mg} \mathrm{L}^{-1}$ & $0,25 \mathrm{mg} \mathrm{L}^{-1}$ & $0,25 \mathrm{mg} \mathrm{L}^{-1}$ \\
Fóforo & $0 \mathrm{mg} \mathrm{L}^{-1}$ & $\mathbf{0 , 8 1 5 7 ~ \mathbf { ~ g ~ L } ^ { - 1 }}$ & $0 \mathrm{mg} \mathrm{L}^{-1}$ & $0 \mathrm{mg} \mathrm{L}^{-1}$ \\
Turbidez & $50 \mathrm{NTU}^{-1}$ & $50 \mathrm{NTU}^{-1}$ & $5050 \mathrm{NTU}^{-1}$ & $50 \mathrm{NTU}^{-1}$ \\
Dureza total & $55 \mathrm{mg} \mathrm{L}^{-1}$ & $85 \mathrm{mg} \mathrm{L}^{-1}$ & $59 \mathrm{mg} \mathrm{L}^{-1}$ & $70 \mathrm{mg} \mathrm{L}^{-1}$ \\
\hline
\end{tabular}

Nota: Origem da amostra: Córrego próximo da escola; Classe-CONAMA: II; Condições climáticas: Tempo nublado; Hora da coleta: 7:30; Data da coleta: 04/06/2013.

Fonte: Baião (2014).

Os motivos da não conformidade com a legislação foram levantados pelos alunos e registrados em planilha. A análise de conteúdo apontou que dos alunos de $6^{\circ}$ ano, 83,3\% (n=24) associaram a presença de amônia e fosfato corretamente ao lixo e ao esgoto, verificados no Ponto 2 durante a visita. Os demais associaram os agentes contaminantes à poluição e ao concreto. Um aluno não fez nenhuma associação. No $7^{\circ}$ ano, $70 \%(\mathrm{n}=21)$ dos alunos justificaram a não conformidade também corretamente com a presença de lixo e esgoto, mas $30 \%(\mathrm{n}=9)$ não fizeram nenhuma associação. Tais resultados vão de encontro ao que Zuin et al. (2009) descreveram em atividades de análise de água proposta aos alunos do Ensino Fundamental e Médio, constatando que os alunos correlacionaram a possível presença de esgoto com baixos valores de oxigênio dissolvido e alto valor de condutividade.

\section{IPABH}

Rev. Ambient. Água vol. 11 (suplemento) Taubaté, 2016 
Em estudo conjunto, a atividade de análise de água proposta neste estudo foi concluída integralmente por mais de $70 \%$ do total de alunos das duas séries, os quais relacionaram as características do entorno do corpo d'água com os resultados obtidos na análise da água.

A análise de bactérias do grupo coliformes foi realizada no Laboratório de Processos Biológicos Aplicados ao Meio Ambiente do Departamento de Ciências Agrárias da Universidade de Taubaté (UNITAU). A contagem de coliformes totais e coliformes termotolerante, nos quatro pontos analisados, mostrou nos Pontos 1 e 2 a presença de mais de $1,6 \times 105 \mathrm{NMP} / 100 \mathrm{~mL}$ tanto em coliformes totais quanto em coliformes termotolerante. No Ponto 3 a contagem foi de 2,4 x 103 NMP/100mL e no Ponto 4 de 9,2 x 104 NMP/100mL para coliformes totais. No entanto, a contagem de coliformes termotolerante no ponto 3 foi de 240 NMP/100mL e no ponto 4 foi de 17 NMP/100mL. De acordo com a Portaria MS No 2914 (Brasil, 2011) que dispõe sobre os procedimentos de controle e de vigilância da qualidade da água para consumo humano e seu padrão de potabilidade, as amostras analisadas não estão dentro dos padrões estabelecidos para potabilidade da água. Para água de consumo humano não é permitida a presença de coliformes totais e termotolerante.

Os resultados obtidos deixam nítida a diferença do número inferior de coliformes, principalmente os termotolerante, apresentado nos pontos 3 e 4 . Os alunos perceberam tal diferença após a apresentação dos resultados, em forma de tabela comparativa, estimulando a observação e a análise dos dados presentes. Múltiplas discussões foram geradas em sala de aula a respeito dos motivos dessas diferenças. Oralmente os alunos manifestaram suas opiniões, concluindo que havia presença de esgoto nos pontos estudados, sobretudo nos Pontos 1 e 2, corroborando os resultados encontrados na análise físico-química.

De acordo com os PCNs de Ciências (Brasil, 1998a), o desenvolvimento de atividades em campo possibilita a percepção de fenômenos e processos naturais presentes no ambiente como um todo e explora aspectos relacionados com os impactos provocados pela ação humana nos ambientes. Assim, o embasamento teórico para as respostas dos alunos, possivelmente, foi construído com a visita à bacia e complementado com a contribuição da apresentação em mídia realizada no início da atividade, a qual mostrava as fontes para os diversos elementos presentes na água, tendo o lixo e o esgoto como os principais agentes poluidores.

O questionário avaliativo pós-atividade apontou que mais de $50 \%$ dos alunos, das duas séries analisadas, reconhecem a presença de diversos elementos físico-químicomicrobiológicos presentes num rio, conforme mostrado na Figura 3. Os demais elementos citados estão indiretamente relacionados às fontes ou ao controle desses elementos na água. $\mathrm{Na}$ categoria elementos físico-químicos foram agrupadas respostas como "Presença de oxigênio", "Presença de ferro", "Presença de fósforo", "Temperatura", entre outros.

Com relação à questão sobre "o que prejudica a qualidade da água", os alunos reconhecem o lixo, esgoto, resíduos industriais, criação de animais, microrganismos patogênicos e alterações físico-químicas como fatores prejudiciais, sobretudo para os alunos do $6^{\circ}$ ano. No item "alterações físico-químicas" foram agrupados todos os comentários referentes aos componentes físico-químicos da água listados pelos alunos, como "falta de oxigênio", "pH alto", "muita amônia", entre outros.

É possível observar nestas questões que os elementos físico-químico-microbiológicos tiveram maior percepção por parte dos alunos do $6^{\circ}$ ano. E que os elementos macroscópicos, como mata ciliar, construções inadequadas, criação de animais e erosão foram mais percebidos pelo $7^{\circ}$ ano. Embora as aulas tenham ocorrido em dias diferentes, os horários das atividades, os materiais utilizados e a intervenção do professor aconteceram em iguais condições nas duas séries. Observou-se que tenha havido motivação maior do $6^{\circ}$ ano para o desenvolvimento de análise de água com o kit de reagentes educativo, enquanto o $7^{\circ}$ ano tenha tido maior motivação para a aula em campo com a visita à bacia. 


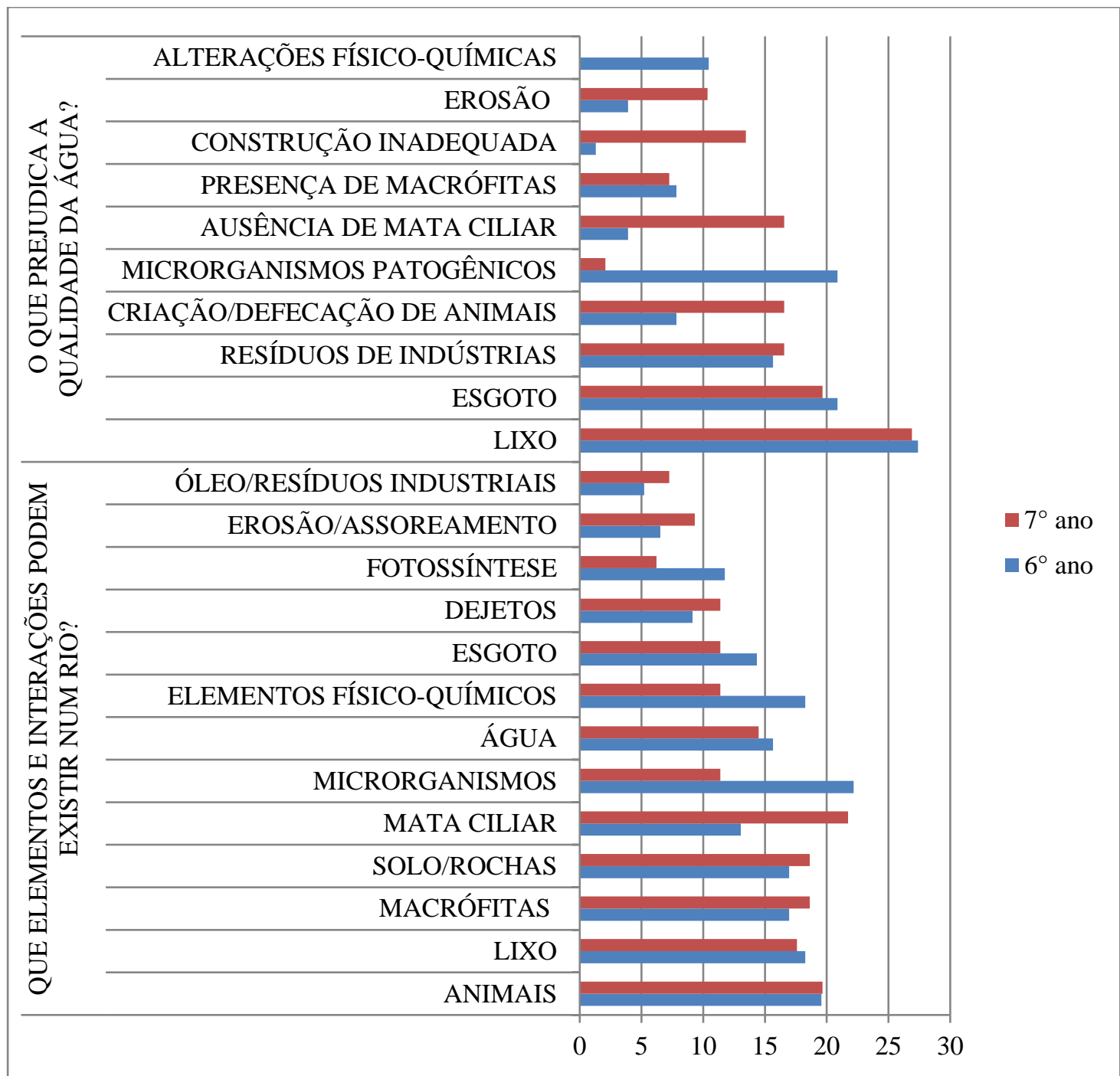

Figura 3. Frequência simples de respostas dos alunos de $6^{\circ}$ ano $(n=30)$ e $7^{\circ}$ ano $(n=30)$ na questão "Que elementos e interações existem num rio?" e "O que prejudica a qualidade da água?"do questionário pós-atividade (Frequência mínima = 5).

Fonte: Baião (2014).

As macrófitas são citadas como fatores prejudiciais provavelmente por serem indicadoras de ambientes alterados. Como foram presenciadas pelos alunos nos locais de estudo, em conjunto com outros fatores prejudiciais, os alunos podem ter confundido sua real função. $\mathrm{O}$ que torna necessária uma retomada nesse aspecto, ressaltando inclusive sua função ecológica de purificação da água, sendo algumas espécies utilizadas como fitorremediadoras de áreas contaminadas com coliformes, conforme ressaltado em Curutchet et al. (2011) ou com sua utilização em tratamento de efluentes (Batista et al., 2005).

A avaliação pós-atividade mostrou diversas interpretações sobre o que prejudica a qualidade da água e o que deve ser feito para sua preservação, mas todas eng Lobando o entorno ambiental para a preservação da Bacia do Rio Comprido e todas remetem a algum ponto do roteiro de atividade proposto. Na visita à bacia, os alunos puderam observar a presença de lixo e esgoto em alguns pontos assim como a criação de animais e a pavimentação do leito, mas também a ausência de mata ciliar. A apresentação em mídia forneceu subsídios teóricos para que os alunos entendessem as fontes dos elementos físico-químico-microbiológicos.

As principais construções de conhecimento dos alunos neste roteiro de atividades permeiam as esferas conceituais, procedimentais e atitudinais. Desenvolveram conceitos

\section{IPABH}

Rev. Ambient. Água vol. 11 (suplemento) Taubaté, 2016 
relacionados aos elementos e interações físico-químico-microbiológicas, naturais e antrópicos, que ocorrem numa bacia hidrográfica. Observaram que além de inúmeros elementos macroscópicos presentes numa bacia existe na água a presença de inúmeros elementos que só podem ser constatados por meio de análise química. Entenderam que, embora a água esteja limpa, não significa que seja potável e, portanto não é adequado o seu consumo sem o conhecimento de sua qualidade, a fim de evitar doenças de veiculação hídrica. Conseguiram, mesmo que em conjunto com o professor, realizar procedimento de avaliação da qualidade da água de 4 trechos de um corpo d'água próximo de suas residências, e finalmente, levantaram hipóteses pertinentes no âmbito socioambiental para explicar os resultados encontrados, relacionadas principalmente à presença inadequada de lixo e esgoto na bacia estudada.

A vivência com o material concreto, oferecido pelo kit de análise de água, foi de fundamental importância para a construção de conteúdos conceituais relacionados aos elementos físico-químicos e de conteúdos procedimentais de análise de água. Gerou enorme envolvimento dos alunos para realizar a atividade e investigar a qualidade da água do córrego da Bacia do Rio Comprido. Relataram sentir-se como cientistas investigando elementos da água. Para Chung e Lima (2007), a vivência com materiais concretos como os kits de análise de água, permite que os alunos aprimorem suas capacidades cognitivas para a construção do conhecimento e reconheçam a necessidade de mobilização da comunidade e da escola para preservar o meio ambiente. Zuin et al. (2009) acrescentam que o intenso envolvimento dos alunos nestas atividades, pode leva-los à reflexão sobre o seu papel na sociedade. De acordo com Belo e Paranhos (2011), as atividades experimentais, se conduzidas adequadamente, podem contribuir para uma aprendizagem significativa de conceitos científicos, pois sua natureza investigativa propicia interpretações, discussões e confrontos de ideias entre os estudantes, assim como o desenvolvimento de importantes habilidades como a capacidade de reflexão, de efetuar generalizações e de realização de atividades em equipe.

$\mathrm{O}$ roteiro de atividades de análise de água colabora para atender aos objetivos do ensino de Ciências de acordo com os PCNs (Brasil, 1998a), pois trabalha com os alunos a coleta, organização, interpretação e a compreensão de informações sobre transformações antrópicas nos ambientes, assim como, medidas de proteção e recuperação, particularmente da região em que vivem. Ele permite também se investigar as alterações ambientais como resultado da emissão de poluentes, os processos de dispersão, a influência da cultura e da economia e a importância das medidas de saneamento e de controle de poluição. No ensino de Geografia, os resultados obtidos por meio deste roteiro também podem ser objetos de discussão sobre as relações de consumismo e poluição, assim como as relações entre o modo de vida urbana e a poluição ambiental (Brasil, 1998b). Assim, acredita-se que a análise da qualidade da água nestas séries tenha incutido maior significado aos conteúdos previstos além de alertar os alunos sobre a importância da preservação da bacia para a qualidade da água, bem como conscientizá-los sobre suas responsabilidades com o meio.

\section{CONCLUSÃO}

O protocolo de avaliação da qualidade físico-químico-microbiológica da água elaborado para ser aplicado por alunos dos $6^{\circ}$ e $7^{\circ}$ anos do Ensino Fundamental em trechos de corpos d'água próximos à escola mostrou-se adequado a estas séries tanto pela motivação provocada nos alunos quanto pelos resultados de aprendizagem do ambiente que vivem.

O enorme interesse e envolvimento demonstrado pelos alunos na realização de atividades diferenciadas do cotidiano escolar, que envolvem aulas de campo, apresentações em mídia atrativas e aulas experimentais elaboradas cuidadosamente para adequar linguagens e conceitos ao nível e ao contexto escolar, gerou a motivação inicial necessária para o desenvolvimento das atividades. 
Os resultados observados mostraram que os alunos perceberam a influência do entorno socioambiental na qualidade da água assim como desenvolveram concepções ambientais expressos em depoimentos e em atitudes durante a realização das atividades. Entretanto, alguns conceitos precisam ser retomados com os alunos, sobretudo quanto à importância ambiental das macrófitas e o seu papel como indicadora de ambientes alterados por excesso de matéria orgânica. Um aprofundamento teórico adequado a estas séries poderia ser realizado com visitas a locais que fazem o tratamento de efluentes por leito de raízes.

Assim a visita à bacia, a apresentação em mídia e a análise com utilização do kit de reagentes de análise físico-química da água bem como análise microbiológica, constituíram um roteiro rico e estimulante para o desenvolvimento de conteúdos programáticos bem como para desenvolvimento da percepção ambiental dos alunos.

\section{REFERÊNCIAS}

BAIÃO, C. F. P. Contribuição metodológica para ampliação da concepção ambiental no Ensino Fundamental com base no estudo de bacia hidrográfica. 2014. Dissertação (Mestrado em Ciências Ambientais) - Departamento de Ciências Agrárias, Universidade de Taubaté, Taubaté, 2014.

BATISTA, G. T.; FORTES NETO, P.; DIAS, N. W.; TARGA, M. S.; OLIVEIRA, L. A. M. Educação ambiental voltada para recursos hídricos: um estudo de caso. 2005. p. 120. Disponível em: http://www.agro.unitau.br:8080/dspace/bitstream/2315/61/1/Ed _Amb_Rec_Hid_Dspace.pdf. Acesso em: 11 fev. 2014.

BELO, C. DE L. A.; PARANHOS, R. O uso da água como tema gerador em uma atividade pedagógica de conscientização ambiental. Experiências em Ensino de Ciências, v. 6, n. 1, p. 7-20, 2011.

BRASIL. Lei n ${ }^{\circ}$ 9433, de 8 de janeiro de 1997. Política Nacional de Recursos Hídricos. Diário Oficial [da] União, Brasília, DF, 09 jan. 1997.

BRASIL. Lei no 9795, de 27 de abril de 1999. Política Nacional de Educação Ambiental. Diário Oficial [da] União, Brasília, DF, 28 abr. 1999.

BRASIL. Ministério do Interior. Portaria nº 86, de 04 de junho de 1981. Enquadra os cursos d'água da Bacia Hidrográfica do Rio Paraíba do Sul. 1981. Disponível em: http://www.ambiente.sp.gov.br/wp-content/uploads/cea/PortariaMinter.pdf. Acesso em: 29 set. 2013.

BRASIL. Ministério da Saúde. Portaria no 2914, de 12 de Dezembro de 2011. Dispõe sobre os procedimentos de controle e de vigilância da qualidade da água para consumo humano e seu padrão de potabilidade. Diário Oficial [da] União, Brasília, DF, 14 dez. 2011.

BRASIL. Secretaria de Educação Fundamental. Parâmetros curriculares nacionais: ciências naturais. Brasília: MEC/SEF, 1998a. 138 p.

BRASIL. Secretaria de Educação Fundamental. Parâmetros curriculares nacionais: geografia. Brasília: MEC/SEF, 1998b. 156 p.

BRASIL. Secretaria de Educação Fundamental. Parâmetros curriculares nacionais: terceiro e quarto ciclos: apresentação dos temas transversais. Brasília: MEC/SEF, 1998c. 436 p. 
CHUNG, F. G.; LIMA, M. M. V. DE. Educação Ambiental com Ênfase na Preservação dos Recursos Hídricos no Município de Campos do Jordão-SP. In: SEMINÁRIO DE RECURSOS HÍDRICOS DA BACIA HIDROGRÁFICA DO PARAIIBA DO SUL: O EUCALIPTO E O CICLO HIDROLÓGICO, 2007, Taubaté. Anais eletrônicos... Taubaté: IPABHi, 2007. Disponível em: http://www.agro.unitau.br/serhidro/doc/pdfs/ 131-137.pdf. Acesso em: 11 fev. 2014.

COMPANHIA AMBIENTAL DO ESTADO DE SÃO PAULO - CETESB. Qualidade das águas interiores no Estado de São Paulo. São Paulo: CETESB, 2008. Disponível em http://cetesb.sp.gov.br/aguas-interiores/wp-content/uploads/sites/32/2013/11/variaveis.pdf Acesso em 28/12/2015.

CONSELHO NACIONAL DO MEIO AMBIENTE - CONAMA. Resolução no 357 de 17 de março de 2005. Dispõe sobre a classificação dos corpos de água e diretrizes ambientais para o seu enquadramento. Diário Oficial [da] União, Brasília, DF, 18 mar. 2005.

CURUTCHET, G.; GRINBERG, S.; GUTIÉRREZ, R. A. Degradación ambiental y Periferia Urbana: Un Estudio Transdiciplinario sobre la Contaminación en la Región Metropolitana de Buenos Aires. Ambiente \& sociedade, v. 15, n. 2, p. 173-194, 2011. http://dx.doi.org/10.1590/S1414-753X2012000200010

JACOBI, P. Educação ambiental, cidadania e sustentabilidade. Cadernos de Pesquisa, n. 118, p. 189-205, 2003. http://dx.doi.org/10.1590/S0100-15742003000100008

KUDRYAVTSEV, A.; KRASNY, M. E.; SDEDMAN, R. C. The impact of environmental education on sense of place among urban youth. Ecosphere, v. 3, n. April, 2012. http://dx.doi.org/10.1890/ES11-00318.1

LUCATTO, L. G.; TALAMONI, J. L. B. A construção coletiva interdisciplinar em educação ambiental no ensino médio: a microbacia hidrográfica do Ribeirão dos Peixes como tema gerador. Ciência e Educação, v. 13, n. 3, p. 389-398, 2007. http://dx.doi.org/10.1590/S1516-73132007000300008

MAKINODAN, D. Y.; COSTA, S. M. F. da C. Estudo das características socioeconômicas e ambientais da microbacia do Rio Comprido. In: ENCONTRO NACIONAL DE ESTUDOS POPULACIONAIS, 14., 2004, Caxambu. Anais eletrônicos... Caxambu: ABEP, 2004. Disponível em: http://www.abep.nepo.unicamp.br/site_eventos_abep /PDF/ABEP2004_95.pdf. Acesso em: 12 ago. 2016.

MORAES, R. Análise de conteúdo. Revista Educação, v. 22, n. 37, p. 7-32, 1999.

PARRON, L. M.; MUNIZ, D. H. de F.; PEREIRA, C. M. Manual de procedimentos de amostragem e análise físico-química de água. Dados eletrônicos. Colombo: Embrapa Florestas. 2011. p. 69. Disponível em: http://www.infoteca.cnptia.embrapa.br /bitstream/doc/921050/1/Doc232ultimaversao.pdf. Acesso em: 18/05/2016.

PORTO, M. F. A.; PORTO, R. L. L. Gestão de bacias hidrográficas. Estudos avançados, v. 22, n. 63, p. 43-60, 2008. http://dx.doi.org/10.1590/S0103-40142008000200004

SCHIEL, D.; MASCARENHAS, S.; VALEIRAS, N.; SANTOS, S. A. M. (Orgs.). O estudo de bacias hidrográficas: uma estratégia para educação ambiental. São Carlos: Rima, 2002.

TUNDISI, J. G. Recursos hídricos no futuro: problemas e soluções. Estudos avançados, v. 22, n. 63, p. 7-16, 2008. http://dx.doi.org/10.1590/S0103-40142008000200002 
ZUIN, V. G.; IORIATTI, M. C. S.; MATHEUS, C. E. O emprego de parâmetros físicos e químicos para a avaliação da qualidade de águas naturais: uma proposta para a educação química e ambiental na perspectiva CTSA. Química e Sociedade, v. 31, n. 1, p. 3-8, 2009. 